\title{
OPTIMIZING CONDITIONS FOR REFINING UNSATURATED FATTY ACIDS FROM HIPPOPHAE RHAMNOIDES L. SEED OIL BY MOLECULAR DISTILLATION USING RESPONSE SURFACE METHODOLOGY
}

\author{
H. Zhang, H.M. Li, S. WANG and F. FenG* \\ Department of Food Science and Nutrition, Zijingang Campus, Zhejiang University, Hangzhou 310058. China \\ Fuli Institute of Food Science, Zijingang Campus, Zhejiang University, Hangzhou 310058. China
}

(Received: 9 April 2013; accepted: 2 August 2013) The refinement of unsaturated fatty acids (UFA) from Hippophae rhamnoides L. seed oil was carried out by
molecular distillation (MD) using response surface methodology (RSM). A central composite rotate design was used
in order to optimize the experimental parameters: distilling temperature and feed flow. The optimal MD conditions
were determined and the quadratic response surfaces were drawn from the mathematical models. The results
suggested that the distilling temperature and feed flow significantly affected both the UFA content and oil yield in
the two models. The optimum conditions for refining UFA were: distilling temperature $107.5^{\circ} \mathrm{C}$ and feed flow $1 \mathrm{ml}$
$\mathrm{min}^{-1}$. Optimal values predicted by RSM for the UFA content and oil yield were $82.38 \%$ and $62.59 \%$, respectively.
Close agreement between experimental and predicted values was obtained.

Keywords: molecular distillation, unsaturated fatty acid, Hippophae rhamnoides L. seed oil, response surface methodology

Hippophae rhamnoides L. (sea buckthorn) is a hardy bush, which belongs to the Elaeagnaceae family and naturally distributes over Asia and Europe (DAVIS, 1982). Hippophae rhamnoides L. seed contains about 9-20\% (w/w) oil. The main characteristic of H. rhamnoides L. seed oil is the high content of unsaturated fatty acids (UFA), such as oleic (15-20\%), linoleic (30-40\%), and $\alpha$-linolenic (23-36\%) acids (BEREZHNAYA et al., 1993; JoHANSSON et al., 1997), which have been reported to play crucial role in the human health (RocHe, 1999).

Molecular distillation (MD) is a gentle method appropriate for the separation and purification of thermally unstable materials as well as compounds with a low vapour pressure and high molecular weight, without the hazard of thermal decomposition (Micov et al., 1997). This method is characterized by a short exposure of the distilled liquid to elevated temperatures, high vacuum in the distillation space, and small distance between the evaporator and the condenser (Cvengros, 1995). MD applications related to vegetable oils are subjects of recent research, such as free fatty acids separation from vegetable oil (MARTINs et al., 2006) and grape seed oil deacidification (MARTINELlo et al., 2007).

Response surface methodology (RSM) is effective for responses that are influenced by many factors and their interactions, which was originally described by Box and WILSON (1951). Many studies indicated that it is useful for developing, improving, and optimizing processes (AtKinson \& Donev, 1992; MARTín-Martínez et al., 2003).

Though the $H$. rhamnoides L. (sea buckthorn) seed oil refined by multiple-stage molecular distillation is available on the market, the objective of the present work is to

\footnotetext{
* To whom correspondence should be addressed.

Phone: +86-571-88982981; fax: +86-571-88982981; e-mail: fengfq@zju.edu.cn
} 
evaluate the influence of MD operative conditions, specifically evaporation temperature and feed flow by RSM, in order to obtain the highest UFA content and to maintain the yield in the distilled product as large as possible. The detailed process and the effect of MD conditions on the oil refinement are described through mathematical models for the first time.

\section{Materials and methods}

\subsection{Materials}

Crude Hippophae rhamnoides L. (sea buckthorn) seed oil was extracted by the method of supercritical fluid $\mathrm{CO}_{2}$ extraction and provided by Qinghai Kangpu Biological Technology Co., Ltd, China. The UFA contents of the crude H. rhamnoides L. (sea buckthorn) seed oil were: $13.1 \%$ oleic acid, $24.7 \%$ linoleic acid, and $21.2 \% \alpha$-linolenic acid. All solvents/ chemicals were of the highest purity grade (above 99\%), purchased from Sigma and used without further purification. Double-distilled water was used in all experiments.

\subsection{Experimental design}

RSM was used for the modelling and analysis of the MD process. The experimental design employed for this analysis was a central composite design. The experiments consisted of 13 runs with two factors (evaporation temperature and feed flow) and five replicates of the central point for the estimation of pure error (Table 1). The response variables considered were UFA content in the refined oil $\left(\mathrm{Y}_{1}\right)$ and oil yield $\left(\mathrm{Y}_{2}\right)$. Oil yield is calculated as the relation of the mass of refined oil and the mass of crude oil that is fed to the molecular distillation step.

Table 1. Central composite design arrangement and responses

\begin{tabular}{|c|c|c|c|c|c|}
\hline \multirow{2}{*}{$\begin{array}{l}\text { Natural variables } \\
\text { Temperature } \\
\mathrm{T}\left({ }^{\circ} \mathrm{C}\right)\end{array}$} & \multicolumn{3}{|c|}{ Coded variables } & \multicolumn{2}{|c|}{ Responses } \\
\hline & $\begin{array}{c}\text { Feed flow } \\
\mathrm{F}\left(\mathrm{ml} \mathrm{min} \mathrm{min}^{-1}\right)\end{array}$ & $\mathrm{X}_{1}$ & $X_{2}$ & $\begin{array}{c}\text { UFA content } \\
\mathrm{Y}_{1}(\%)\end{array}$ & $\begin{array}{c}\text { Oil yield } \\
Y_{2}(\%)\end{array}$ \\
\hline 110 & 0.5 & 1 & -1 & 76.35 & 27.55 \\
\hline 110 & 1.5 & 1 & 1 & 76.05 & 66.11 \\
\hline 100 & 0.5 & -1 & -1 & 76.76 & 48.42 \\
\hline 100 & 1.5 & -1 & 1 & 66.33 & 73.85 \\
\hline 98 & 1 & -1.414 & 0 & 76.75 & 71.83 \\
\hline 105 & 1.7 & 0 & 1.414 & 76.40 & 73.65 \\
\hline 112 & 1 & 1.414 & 0 & 79.09 & 51.01 \\
\hline 105 & 0.3 & 0 & -1.414 & 73.75 & 8.35 \\
\hline 105 & 1 & 0 & 0 & 82.12 & 67.29 \\
\hline 105 & 1 & 0 & 0 & 82.30 & 65.51 \\
\hline 105 & 1 & 0 & 0 & 82.01 & 67.91 \\
\hline 105 & 1 & 0 & 0 & 83.19 & 66.82 \\
\hline 105 & 1 & 0 & 0 & 81.99 & 65.98 \\
\hline
\end{tabular}


The relations between the coded and natural variables, for evaporation temperature and for feed flow, are given by Eqs. (1) and (2) as

$$
\begin{aligned}
& \mathrm{X}_{1}=\frac{\mathrm{T}-\mathrm{T}_{\mathrm{c}}}{\Delta \mathrm{T}} \\
& \mathrm{X}_{1}=\frac{\mathrm{F}-\mathrm{F}_{\mathrm{c}}}{\Delta \mathrm{F}}
\end{aligned}
$$

where $\mathrm{X}_{1}$ and $\mathrm{X}_{2}$ are the coded values, $\mathrm{T}$ and $\mathrm{F}$ are the corresponding natural values. $\mathrm{T}_{\mathrm{c}}$ and

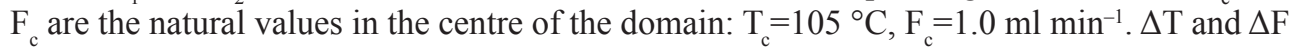
are the increments of $\mathrm{T}$ and $\mathrm{F}$ corresponding to one unit of $\mathrm{X}_{1}$ and $\mathrm{X}_{2}$ respectively: $\Delta \mathrm{T}=5^{\circ} \mathrm{C}$,

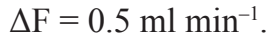

\subsection{Distillation of UFA by $M D$}

The distillation was performed using a laboratory wiped film molecular distillator model KDL 5, GmbH UIC (Alzenau, Germany), which is a variation from falling film molecular distillation with agitation. The major part of the equipment was constructed from glass. The heating of the evaporator was provided by a jacket circulated with heated oil from an oil bath. The vacuum system included a diffusion and a mechanical pump. The surface area of the evaporator is $0.048 \mathrm{~m}^{2}$ and the surface area of internal condenser is $0.065 \mathrm{~m}^{2}$. The equipment is shown in Figure 1.

Some of the operative conditions were fixed in typical values according to the operation manual. For practical operation, the vacuum was $0.1 \mathrm{~Pa}$, the feed temperature was $45^{\circ} \mathrm{C}$, the condensation temperature was $45^{\circ} \mathrm{C}$, and the roller wiper speed inside the evaporator was fixed at 415 r.p.m., while feed flow and evaporation temperature were varied in order to optimize the operation conditions.

The feed was heated to melt and admitted into still. After setting the parameters, the feeding valve was turned on and the degassed feed liquid was immediately forced quickly down the evaporating surface and spread to a very thin film by a scraper. Heated walls and high vacuum drive the more volatile components (lighter components) to the closely positioned internal condensing surface (distillates) as the less volatile components (heavier components) continue down the cylinder (residues). The resulting fractions, thus separated, exit through individual discharge outlets. The distillates were collected as the refined oil to calculate the oil yield and determine UFA content.

\subsection{Determination of UFA content}

The saponification pretreatment of the refined oil was conducted according to the official methods (GB/T 15687-1995, eqv ISO 661:1989) of Approved National Standards of P. R. ChInA (1995). The analytical determination of UFA was conducted in a SP-6890 gas chromatograph (Shandong Lunan Ruihong Chemical Instrument Corporation, China) connected to a DB-23 capillary column $(60 \mathrm{~m} \times 0.25 \mathrm{~mm} \times 0.25 \mu \mathrm{m}$; Agilent, USA $)$ using nonadecanoic acid as an internal standard. The carrier gas was nitrogen. The column temperature was controlled at $190{ }^{\circ} \mathrm{C}$. The injector and detector temperatures were $260{ }^{\circ} \mathrm{C}$ and $270{ }^{\circ} \mathrm{C}$, respectively. 


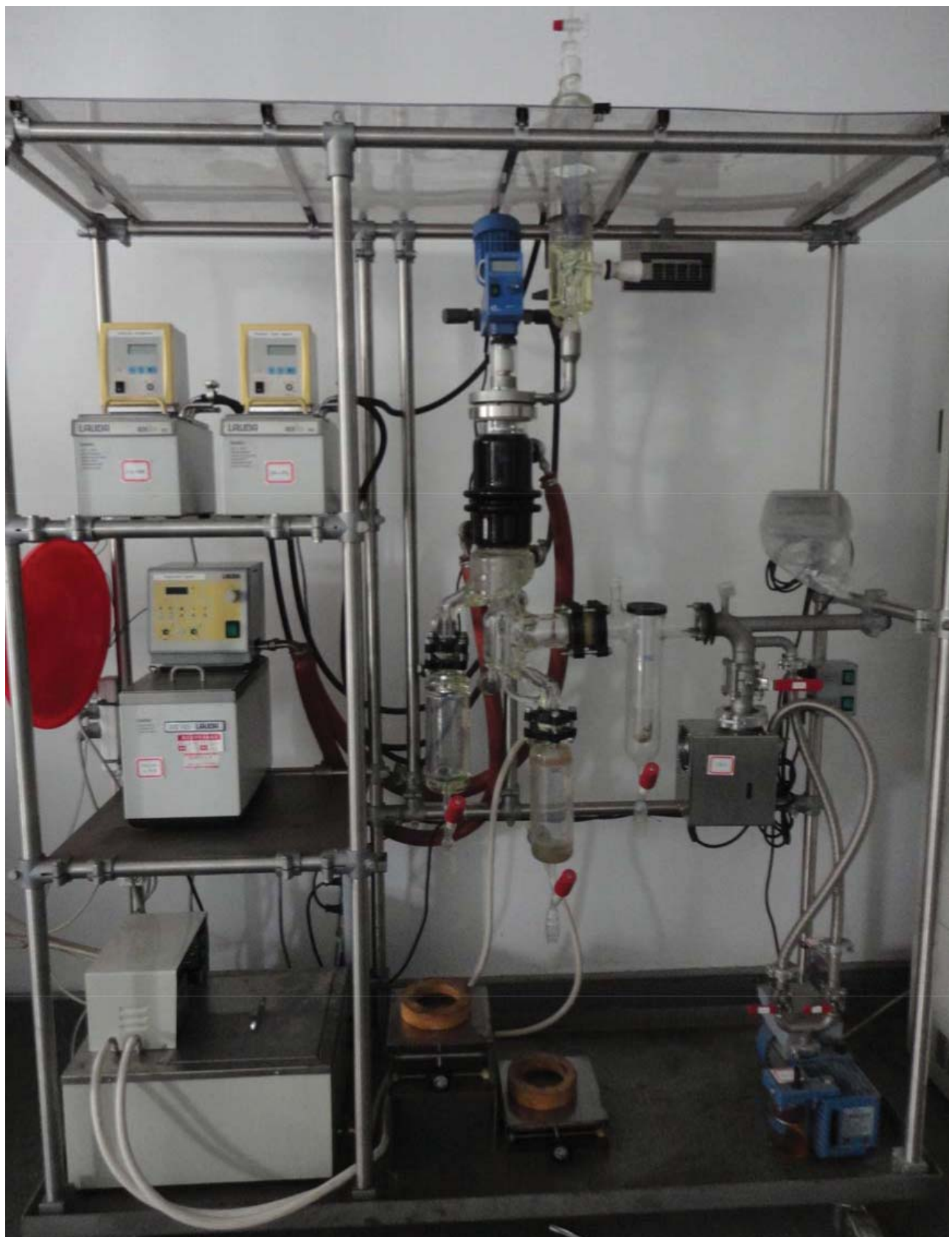

Fig. 1. The molecular distillation (MD) equipment used in the experiment

\subsection{Statistical analysis}

The software SPSS 16.0 was used to analyze the experimental data. The model proposed for each response was a second order model, whose coefficients were generated by regression Acta Alimentaria 44, 2015 
analysis. The fitness of the model was evaluated by the correlation coefficient $\mathrm{R}^{2}$, the fraction of the variation explained by the model, and an analysis of variance (F-test). The F-test is applied to confirm whether the variance explained by the regression model is significantly larger than the variance of the residual, and to evaluate the model lack of fit (model error).

The normal and independent distribution of residuals, which is required for the employment of hypothesis testing procedures, were checked with the normal probability plot of residuals, the plot of residuals vs. temperature, and the plot of residuals vs. feed flow.

The effects of the variables were displayed in surface and contour plots.

\section{Results and discussion}

The UFA content $\left(\mathrm{Y}_{1}\right)$ and oil yield $\left(\mathrm{Y}_{2}\right)$ for each set of variable combinations during $\mathrm{MD}$ are shown in Table 1. Multiple regression coefficients were calculated by employing the least square technique to predict quadratic polynomial models for $\mathrm{Y}_{1}$ and $\mathrm{Y}_{2}$. The regression analysis for the two responses indicated that results were highly significant $(\mathrm{P}<0.05)$ under the models, respectively, therefore they could be used for explanation of the responses observed.

\subsection{UFA content}

To examine conditions that might affect the UFA content $\left(\mathrm{Y}_{1}\right)$ of refined oil, its regression model was predicted by Eq. (3) as follows:

$$
\mathrm{Y}_{1}=82.302+1.579 \mathrm{X}_{1}-0.873 \mathrm{X}_{2}-2.847 \mathrm{X}_{1}^{2}-4.27 \mathrm{X}_{2}^{2}+2.532 \mathrm{X}_{1} \mathrm{X}_{2}
$$

The correlation coefficients were high enough for a response surface: $R^{2}=0.827$, Adjusted $\mathrm{R}^{2}=0.703$. Table 2 shows the variance analysis of the regression model on the UFA content of the refined oil. The complete quadratic model showed an excellent fit $(\mathrm{P}=0.014<0.05)$; furthermore, it appeared to reasonably represent the data. Thus, the responses were sufficiently explained by the regression equation.

Table 2. ANOVA of quadratic polynomial model on the UFA content

\begin{tabular}{lccccc}
\hline $\begin{array}{l}\text { Source of } \\
\text { variation }\end{array}$ & Sum of squares & $\begin{array}{c}\text { Degrees of } \\
\text { freedom }\end{array}$ & Mean square & F & P \\
\hline Regression & 215.627 & 5 & 43.125 & 6.682 & 0.014 \\
Residual & 45.178 & 7 & 6.454 & & \\
Total & 260.805 & 12 & & & \\
\hline
\end{tabular}

The significance analysis of regression coefficients for this model was given in Table 3. There was a high significant regression $(\mathrm{P}<0.05)$ relationship between the dependent variable $\left(Y_{1}\right)$, which responds to the UFA content of the refined oil, and the two responding variables, $\mathrm{X}_{1}$ and $\mathrm{X}_{2}$, which represent distilling temperature and feed flow, respectively. According to this model, quadratic terms of distilling temperature $\left(\mathrm{X}_{1}^{2}, \mathrm{P}<0.05\right)$ and feed flow $\left(\mathrm{X}_{2}^{2}, \mathrm{P}<0.05\right)$ reached high significance. The result suggested that distilling temperature and feed flow had a significant effect on the UFA content of the refined oil. In contrast, the linear terms of 
distilling temperature $\left(\mathrm{X}_{1}\right)$ and feed flow $\left(\mathrm{X}_{2}\right)$ and the interaction of distilling temperature and feed flow $\left(\mathrm{X}_{1} \mathrm{X}_{2}\right)$ were not significant; nevertheless, they were kept in the equation in order to diminish the errors.

Table 3. Significance test of regression coefficients on the UFA content

\begin{tabular}{lccccc}
\hline \multirow{2}{*}{ Model } & \multicolumn{2}{c}{ Unstandardized coefficients } & & Standardized coefficients & \multirow{2}{*}{$\mathrm{P}$} \\
\cline { 2 - 3 } & Coefficient estimate & Standard error & & Beta \\
\cline { 2 - 3 } (Constant) & 82.302 & 1.136 & & 0.000 \\
$\mathrm{X}_{1}$ & 1.579 & 0.898 & 0.277 & 0.122 \\
$\mathrm{X}_{2}$ & -0.873 & 0.898 & -0.153 & 0.363 \\
$\mathrm{X}_{1}{ }^{2}$ & -2.847 & 0.963 & -0.469 & 0.021 \\
$\mathrm{X}_{2}{ }^{2}$ & -4.270 & 0.963 & -0.703 & 0.003 \\
$\mathrm{X}_{1} \mathrm{X}_{2}$ & 2.532 & 1.270 & 0.314 & 0.087 \\
\hline
\end{tabular}

The response surface of UFA content $\left(\mathrm{Y}_{1}\right)$, distilling temperature $\left(\mathrm{X}_{1}\right)$, and feed flow $\left(\mathrm{X}_{2}\right)$ was shown in Fig. 2. From this three-dimensional plot, the region of high content can be easily identified, the effects of distilling temperature and feed flow on the UFA content of the refined oil are reflected: the UFA content is mainly influenced by the distilling temperature or feed flow, but there is not much interaction between the temperature and the flow.

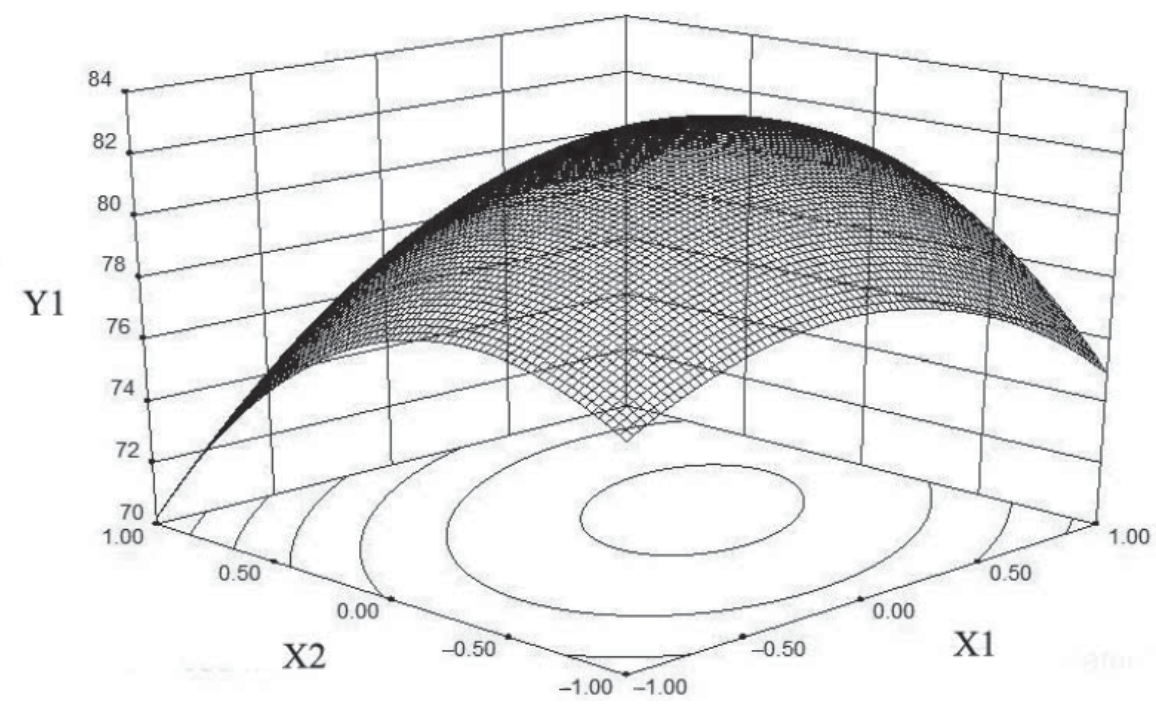

Fig. 2. Response surface for the effects of temperature and feed flow on the UFA content

From Fig. 2 it can be seen that $\mathrm{X}_{1}, \mathrm{X}_{2}$ extreme points exist, the greatest $\mathrm{Y}_{1}$ is estimated as $82.38 \%$, when the two factors point optimal test $\left(\mathrm{X}_{1}, \mathrm{X}_{2}\right)$ of the code value at surface point

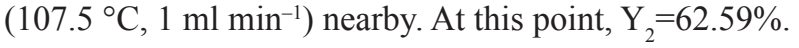


2.2. Oil yield

The regression model of the oil yield was predicted by Eq. (4) as follows:

$$
\mathrm{Y}_{2}=66.702-7.257 \mathrm{X}_{1}+19.543 \mathrm{X}_{2}-1.948 \mathrm{X}_{1}^{2}-12.158 \mathrm{X}_{2}^{2}+3.283 \mathrm{X}_{1} \mathrm{X}_{2}
$$

The correlation coefficients are high enough for a response surface: $\mathrm{R}^{2}=0.974$, adjusted $\mathrm{R}^{2}=0.956$. Table 4 shows the variance analysis of the regression model on the oil yield. The results of the analysis of variation $(\mathrm{F}=53.155, \mathrm{P}<0.005)$ indicated that there is a high statistically significant multiple relationship between the independent variables and the response.

Table 4. ANOVA of quadratic polynomial model on the oil yield

\begin{tabular}{lccccc}
\hline $\begin{array}{l}\text { Source of } \\
\text { variation }\end{array}$ & Sum of squares & $\begin{array}{c}\text { Degrees of } \\
\text { freedom }\end{array}$ & Mean square & F & P \\
\hline Regression & 4548.697 & 5 & 909.739 & 53.144 & 0.000 \\
Residual & 119.829 & 7 & 17.118 & & \\
Total & 4668.527 & 12 & & & \\
\hline
\end{tabular}

The significance analysis of regression coefficients for this model was given in Table 5 . The response variable $\mathrm{Y}_{2}$, which responds to the oil yield, was affected significantly by the linear terms of distilling temperature $\left(\mathrm{X}_{1}, \mathrm{P}<0.01\right)$, feed flow $\left(\mathrm{X}_{2}, \mathrm{P}<0.01\right)$, and quadratic terms of feed flow $\left(\mathrm{X}_{2}^{2}, \mathrm{P}<0.01\right)$, while the interaction of distilling temperature and feed flow $\left(\mathrm{X}_{1} \mathrm{X}_{2}\right)$ and quadratic terms of distilling temperature $\left(\mathrm{X}_{1}^{2}\right)$ had no significant effect on the oil yield.

Table 5. Significance test of regression coefficients on the oil yield

\begin{tabular}{|c|c|c|c|c|}
\hline \multirow[t]{2}{*}{ Model } & \multicolumn{2}{|c|}{ Unstandardized coefficients } & \multirow{2}{*}{$\frac{\text { Standardized coefficients }}{\text { Beta }}$} & \multirow[t]{2}{*}{$\mathrm{P}$} \\
\hline & Coefficient estimate & Standard error & & \\
\hline (Constant) & 66.702 & 1.850 & & 0.000 \\
\hline $\mathrm{X}_{1}$ & -7.257 & 1.463 & -0.300 & 0.002 \\
\hline $\mathrm{X}_{2}$ & 19.543 & 1.463 & 0.809 & 0.000 \\
\hline $\mathrm{X}_{1}^{2}$ & -1.948 & 1.569 & -0.076 & 0.254 \\
\hline $\mathrm{X}_{2}^{2}$ & -12.158 & 1.569 & -0.473 & 0.000 \\
\hline $\mathrm{X}_{1} \mathrm{X}_{2}$ & 3.283 & 2.069 & 0.096 & 0.157 \\
\hline
\end{tabular}

The response surface for the influence of the distilling temperature and feed flow on the oil yield is shown in Fig. 3. From this three-dimensional plot, the oil yield increased as the evaporation temperature decreased, possibly because lower temperature reduced the effective mean free path of the molecules, causing heavier molecules to remain in the residue fraction. At the same distilling temperature, the maximum oil yield existed when feed flow was between $1.25 \mathrm{ml} \mathrm{min}{ }^{-1}$ and $1.50 \mathrm{ml} \mathrm{min}^{-1}$. 


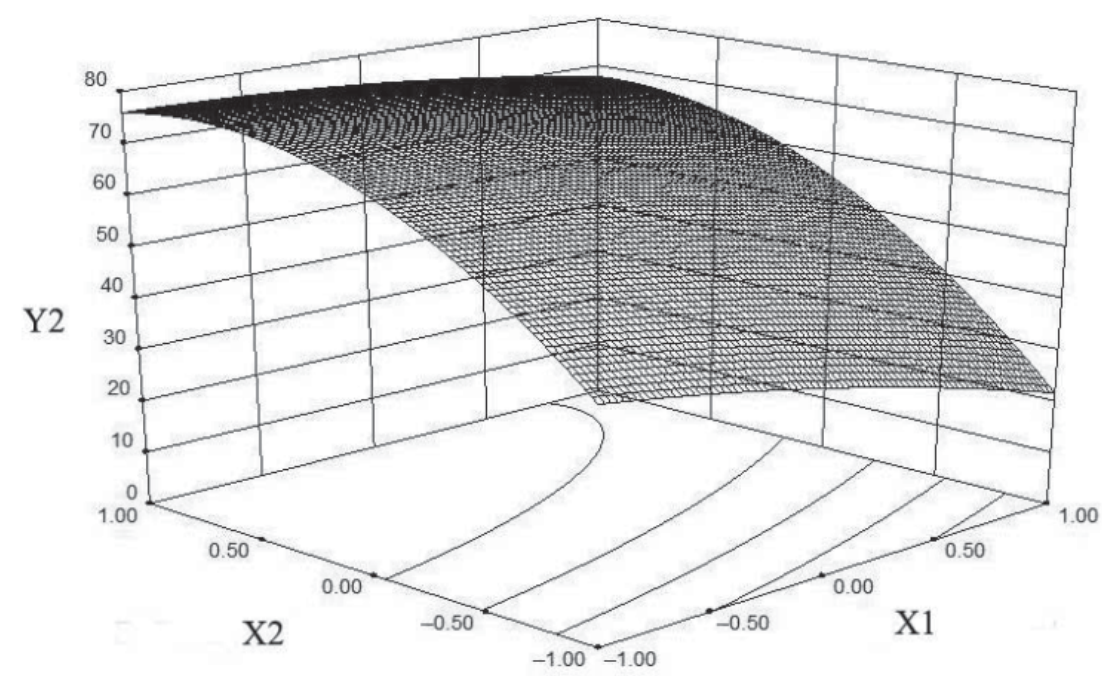

Fig. 3. Response surface for the effects of temperature and feed flow on the oil yield

\subsection{Optimization}

According to the canonical analysis described by KHURI and CORNELl (1987), the stationary points were located for the corresponding responses. In this study, the search criteria were to obtain the highest UFA content, while maintaining the oil yield as large as possible.

Therefore, the optimum MD conditions were obtained as $107.5^{\circ} \mathrm{C}$ and $1 \mathrm{ml} \mathrm{min}^{-1}$ from ridge analysis, which correspond to the distilling temperature and the feed flow, respectively. The adequacy of the model equation for predicting the optimum response values was tested in the experiments using the above MD conditions.

Predicted and experimental values were given in Table 6. The experimental values ( $82.12 \%$ for the UFA content and $62.18 \%$ for the oil yield) were in perfect agreement with the predicted values $(82.38 \%$ for the UFA content and $62.59 \%$ for the oil yield), a result confirming the adequacy of the predicted models (Table 6).

Table 6. Predicted and experimental values of the response at optimum conditions

\begin{tabular}{lcc}
\hline & $\begin{array}{c}\text { Predicted value } \\
(\%)\end{array}$ & $\begin{array}{c}\text { Experimental value } \\
(\%)\end{array}$ \\
\hline UFA content & 82.38 & 82.12 \\
Oil yield & 62.59 & 62.18 \\
\hline
\end{tabular}

\section{Conclusion}

In sum, MD proved to be a proper method for refining UFA from H. rhamnoides L. seed oil. RSM was effective for estimating the effects of the distilling temperature and feed flow of $\mathrm{MD}$, as well as determining the optimal conditions for UFA production. Response surface 
graphs were drawn from the regression models to visualize the robustness of the purification method. The optimal parameters in the process were determined as the distilling temperature

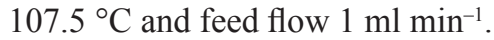

\section{Abbreviations:}

MD: molecular distillation; RSM: response surface methodology; UFA: unsaturated fatty acids; T: evaporation temperature; F: feed flow; P: possibility; $\mathrm{Y}_{1}$ : the UFA content; $\mathrm{Y}_{2}$ : the oil yield.

This paper is part of S. Wang's M.Sc. Thesis, Zhejiang University. The work was financially supported by the National High-tech Research and Development Program (No.2006BAD05A02) and the Fundamental Research Funds for the Central Universities of China.

\section{References}

Atkinson, A.C. \& Donev, A.N. (1992): Optimum experimental designs. Oxford University Press, Oxford, pp. 132189.

Box, G.E.P. \& Wilson, K.G. (1951): On the experimental attainment of optimum conditions. J. R. Stat. Soc. Ser. B-Stat. Methodol., 13, 1-45.

Berezhnaya, G.A., Ozerinina, O.V., Yeliseev, I.P., Tsydendambaev, V.D. \& Vereshchagin, A.G. (1993): Developmental changes in the absolute content and fatty acid composition of acyl lipids of sea buckthorn fruits. Plant Physiol. Biochem., 31, 323-332.

Cvengros, J. (1995): Physical refining of edible oils. J. Am. Oil Chem. Soc., 72, 1193-1196.

Davis, P.H. (1982): Flora of Turkey and the East Aegean Islands. University Press, Edinburgh, pp. $532-534$.

Johansson, A., LaAKso, P. \& Kallio, H. (1997): Characterization of seed oils of wild edible Finnish berries. Z. Lebensm. Unters. Forsch. A, 204, 300-307.

Khuri, A.A. \& Cornell, J.A. (1987): Response surface: design and analyses. Marcel Dekker Inc., New York, pp. 1-17, 254.

Micov, M., Lutisan, J. \& Cvengros, J. (1997): Balance equations for molecular distillation. Sep. Sci. Technol., 32, 3051-3066.

Martinello, M., Hecker, G. \& Pramparo, M.D.C. (2007): Grape seed oil deacidification by molecular distillation: Analysis of operative variables influence using the response surface methodology. J. Fd Engng, 81, 60-64.

Martins, P.F., Ito, V.M., Batistella, C.B. \& Maciel, M.R.W. (2006): Free fatty acid separation from vegetable oil deodorizer distillate using molecular distillation process. Sep. Purif. Technol., 48, 78-84.

Martín-Martínez, E.S., Martín-Martínez, M.R., Martín-Martínez, F. \& Martín-Martínez, J.L. (2003): Selective nixtamalization of fractions of maize grain (Zea mays L.) and their use in the preparation of instant tortilla flours analyzed using response surface methodology. Cereal Chem., 80, 13-19.

National Standard of P.R. China (1995): Animal and vegetable fats and oil - Preparation of test sample. GB/T 15687-1995

Roche, H.M. (1999): Unsaturated fatty acids. Proc. Nutr. Soc., 58, 397-401. 